\title{
O PREPARO DOS ACADÊMICOS DE ENFERMAGEM BRASILEIROS PARA VIVENCIAREM O PROCESSO MORTE-MORRER ${ }^{1}$ AN INVESTIGATION OF HOW BRAZILIAN NURSING UNDERGRADUATES EXPERIENCE THEIR PATIENTS' DEATH-DYING PROCESSES LA PREPARACIÓN DE LOS ESTUDIANTES BRASILEÑOS DE ENFERMERÍA PARA VIVENCIAR EL PROCESO MUERTE-MORIR
}

\author{
Jamine Bernieri', Alice Hirdes ${ }^{3}$
}

${ }^{1}$ Monografia de conclusão de curso de Graduação em Enfermagem.

${ }^{2}$ Enfermeira da Secretaria de Saúde de Quatro Irmãos, RS.

${ }^{3}$ Enfermeira. Docente do Centro Universitário Feevale (FEEVALE). Pesquisadora na área de reabilitação psicossocial e reforma psiquiátrica. Mestre em Enfermagem pela Universidade Federal de Santa Catarina (UFSC).

PALAVRAS-CHAVE: Morte. Estudantes de enfermagem. Emoções. Medicina do comportamento. Enfermagem prática.

KEYWORDS: Death. Nursing students. Emotions. Behavioral medicine. Practical nursing.
RESUMO: Esta pesquisa teve como objetivo geral investigar o preparo dos acadêmicos de enfermagem frente à morte. A metodologia é de natureza qualitativa, realizada através de 15 entrevistas semi-estruturadas com acadêmicos de Enfermagem do sexto e sétimo semestres de uma instituição de ensino superior localizada no norte do Rio Grande do Sul. Os resultados apontam as dificuldades dos acadêmicos de enfermagem entrevistados em lidar com o processo morte-morrer dos pacientes assistidos em estágio; a dificuldade de lidar com os sentimentos de ansiedade, culpa e impotência gerados pela experiência; a fuga do contato com os familiares, através de cuidados emimentemente técnicos e burocráticos; a falta de apoio do professor supervisor em campo de estágio, quando da morte de um paciente e o desconhecimento das fases psicológicas da morte. Conclui-se que os acadêmicos de enfermagem não estão preparados para vivenciar o processo morte-morrer de seus futuros clientes devido às poucas oportunidades de discutir o tema na graduação.

ABSTRACT: This paper aims at investigating how Nursing undergraduates face death. It is a qualitative study; fifteen semi-structured interviews were carried out with nursing undergraduates who attend the third and the fourth years of their course in a college located in northern Rio Grande do Sul, Brazil. Results show the difficulty Nursing undergraduates experience when dealing with their patients' death-dying process during their apprenticeship; the difficulty in dealing with anxiety, guilt, and impotence generated by the experience; the attempt to escape from contact with the patients' relatives by taking on technical and bureaucratic aspects of their work; the apprenticeship professor/supervisor's lack of support when a patient dies; and a lack of knowledge about the psychological phases of death. I have concluded that Nursing undergraduates are not prepared to experience the death-dying process of their patients-to-be due to the fact that they have few opportunities to discuss the theme during their undergraduate course.

PALABRAS CLAVE: Muerte. Estudiantes de enfermería. Emociones. Medicina de la conducta. Enfermería práctica.

RESUMEN: El objetivo general del presente estudio es investigar la preparación delos estudiantes de enfermería ante de la muerte. La metodología empleada es de naturaleza cualitativa, realizada a través de quince entrevistas parcialmente estructuradas con los alumnos de Enfermería del sexto y séptimo semestre de una institución de enseñanza superior localizada al norte del Estado de Río Grande do Sul (RS). Los resultados obtenidos señalan las dificultades que los alumnos de enfermería entrevistados tienen con relación al proceso muerte-morir de los pacientes asistidos durante la pasantía. También la dificultad de relacionarse con sentimientos tales como, ansiedad, culpa e impotencia causados por la experiencia; la fuga del contacto con los familiares, a través de cuidados eminentemente técnicos y burocráticos; la falta de apoyo del profesor supervisor de campo de la pasantía, en caso de muerte de un paciente y el desconocimiento de las fases psicológicas de la muerte. Se concluye que los alumnos de enfermería no están preparados para vivir el proceso muerte-morir de sus futuros clientes debido a las pocas oportunidades que tienen para discutir el tema en la licenciatura.
Endereço: Jamine Bernieri

R. Abraão Agranionik, s/n.

99.720 000 - Quatro Irmãos, RS.

Email: alicehirdes@gmail.com
Artigo original: Pesquisa

Recebido em: 15 de agosto de 2006. Aprovação final: 28 de dezembro de 2006. 


\section{INTRODUÇÃO}

São variados os conceitos ou concepções de morte, masse compararmoso referencial bibliográfico, evidencia-se que todos têm algo em comum; tratam da parada das funções vitais e da separação do corpo e da alma. Nos séculos passados, era considerado como diagnóstico de morte a cessação da respiração e da função cardíaca. Na atualidade, o critério comumente utilizado é uma avaliação da função cerebral, pois com os avanços tecnológicos, se tornou possível manter as funções cardíacas e respiratórias através de aparelhos, como o respirador, enquanto nada pode ser feito para manter as funções cerebrais responsivas. ${ }^{1}$

Énecessário ressaltar que a ciência evoluiu muito, a ponto de se conseguir manter as funções vitais de uma pessoa por dias, meses e anos. A morte é o estágio final do crescimento humano, ${ }^{2}$ as reações e percepções que as pessoas têm diante da vida e da morte estão relacionadas com o tipo de educação que receberam, as experiênciasquevivenciarameocontextosociocultural onde cresceram e se desenvolveram. ${ }^{3}$

A partir do momento em que nos descobrimos finitos, passamos a compreender melhor a finitude do outro, ou seja, dos pacientes. A partir de então, deixamos de encarar a morte como um fracasso de nossa profissão e passamos a percebê-la como algo natural e destinado a todos. ${ }^{4}$

"O mundo ocidental transformou a morte em tabu, ela costuma ser ocultada das crianças e banida das conversas cotidianas". ${ }^{1: 245}$ Os sentimentos que a morte faz aflorar são tão intensos, que seu nome não deve nem ser pronunciado. Por si só ela causa medo, fuga e espanto. ${ }^{3}$

As escolas de enfermagem e medicina devem preparar os profissionais para que, além de serem tecnicamente competentes, sejam capazes de lidar com seus próprios sentimentos e usá-los de modo deliberado e humanamente sofisticados. ${ }^{2}$

"Dar suporte emocional para quem está necessitando, deixando de lado crenças religiosas e preconceitos sobre a morte e passar a ver o paciente terminal como pessoa e sujeito de sua própria vontade, com direito a uma morte digna é o que preconiza a assistência a ser prestada pela enfermagem humanizada". ${ }^{1: 76}$

\section{OBJETIVO}

Esta pesquisa teve como objetivo investigar o preparo dos acadêmicos de enfermagem frente à representação do tema morte.

\section{METODOLOGIA}

O método utilizado caracteriza-se como um estudoexploratório-descritivo, de abordagem qualitativa. Os participantes deste estudo foram quinze acadêmicos do sexto e sétimo semestre do Curso de Graduação em Enfermagem de uma instituição de ensino superior, localizada ao norte do estado do Rio Grande do Sul. Para a coleta dos dados foi utilizada a entrevista através de um questionário semi-estruturado. A pesquisa foi realizada nos meses de março e abril de 2005.

A análise obedeceu à seguinte proposta metodológica: ordenação, classificação e análise final dos dados. ${ }^{5}$ A ordenação dos dados consistiu na transcrição de fitas-cassete; releitura do material; organização dos relatos em determinada ordem, de acordo com a proposta analítica. A classificação dos dados foi operacionalizada através da leitura exaustiva e repetida dos textos. Através deste exercício fez-se a apreensão das estruturas de relevância a partir das falas dos sujeitos do estudo. Nestas estruturas estão contidas as idéias centrais dos entrevistados. A partir das estruturas de relevância foram identificadas as áreas temáticas.

A análise final permitiu fazer uma reflexão sobre o material empírico e analítico, num movimento incessante que se elevou do empírico para o teórico e vice-versa. Esta "dança" que promove relações entre o teórico e o empírico, o concreto e o abstrato, o geral e o particular, ateoriae a práticaéo verdadeiro movimento dialético visando ao concreto pensado.

Os entrevistados encontram-se identificados no texto pelasletras doalfabeto (Acadêmico A, Acadêmico $B, \ldots .$.$) . Foram respeitados os aspectos éticos referentes$ à pesquisa com seres humanos, conforme determina a Resolução $N^{\circ} 196 / 96 .{ }^{6}$ A pesquisa foi submetida e aprovada pelo Comitêde Ética em Pesquisa da Universidade, sob o protocolo $\mathrm{N}^{\mathrm{0}}$ 004-1/TCH/05.

\section{RESULTADOS E DISCUSSÃO}

As áreas temáticas que emergiram da análise de dados foram: a percepção dos acadêmicos de enfermagem frente ao processo morte-morrer e a família; a morte vista como estigma, tabu e misticismo; o preparo para vivenciar o processo morte-morrer; o apoio oferecido pelo professor supervisor em campo; os sentimentos experimentados pelos acadêmicos que vivenciam a morte em campo de estágio; o conhecimento/desconhecimento das fases psicológicas vividas pelo paciente. 
Percepção dos acadêmicos de enfermagem frente ao processo morte-morrer e a família

Esta área temática aborda a percepção dos acadêmicosde enfermagem frente ao processo morte-morrer e à família. As entrevistas evidenciam que a família é considerada muito importante, quando relacionada às questões que envolvam o processo morte-morrer de clientes/pacientes, sendo necessário o suporte por parte da equipe de enfermagem, conforme coloca o depoimento a seguir. Certamente o paciente terminal tem essa passagem mais dolorosa, sofrida, não apenas em relacão ao paciente, mas também à familia. A mesma às vezese está se preparando para a morte, ou pensa que está se preparando, porque quando ela realmente ocorre é possivel perceber sentimentos de perda, distância e separação (Acadêmico O).

Se não levarmos em conta a família do paciente terminal, não poderemos ajudá-lo eficientemente, pois os membros da família passarão por um processo de adaptação nesta nova situação; tal processo é semelhante ao do paciente, sendo a equipe de saúde importante por favorecer este entendimento, proporcionando aosfamiliares uma conscientização a respeito da importância dos sentimentos a serem compartilhados entre eles e o paciente. Tal atitude virá auxiliá-los na preparação da separação iminente, chegando juntos ao processo de aceitação. ${ }^{2}$

Um dos acadêmicos entrevistados salientou a falta de apoio aos familiares por parte dos profissionais. [...] nós pegamos uma paciente com morte cerebral [...] sabe? Então eu me senti assim, eu vi assim cada 10-15 minutos entrava filha, marido, entrava o neto pra vê ela. Dai eu vou cuidar dela se estava à família ali do lado chocada, entende? [...] ou no caso de uma pessoa parar num quarto e a familia está ali ao redor, a familia é colocada para fora do quarto [...], e a família fica lá sozinha. Sai uns desesperados pra um lado, outros pra outro, é uma situação bem difícil (Acadêmico C).

"A interação do enfermeiro com os familiares ocorre se o enfermeiro se mostrar, além de técnico competente, uma pessoa capaz de desenvolver a empatia, a comunicação e a humildade, como instrumentos de trabalho para uma práxis mais humanizada, que seja libertadora e classificadora de responsabilidades dos profissionais enfermeiros".$: 120$ [...] o enfermeiro acompanha diretamente a evolução deste paciente e sua família, e é a pessoa mais próxima que poderia e deveria dar suporte emocional e sentimental, fazer com que a família aceite esta perda e suporte da melhor maneira (Acadêmico N).

Estudos sobre a morte e o morrer revelam que os profissionais, sejam eles quais forem, devem apoiar os familiares do paciente que acabou de falecer, através de atitudes simples, como ficar ao lado daqueles parentes e deixá-los chorar, falar e até gritar, se necessário. $\mathrm{O}$ importante mesmo é o profissional estar ali à disposição das pessoas naquele momento. ${ }^{8}$ Nesta situação, o Acadêmico $\mathrm{N}$ colocou que [...] o enfermeiro acompanha diretamente a evolução deste paciente e sua familia e é a pessoa mais próxima que poderia e deveria dar suporte emocional e sentimental, fazer com que a familia aceite esta perda e suporte da melhor maneira (Académico N).

As entrevistas revelam que o diálogo com os familiares do paciente terminal, bem como o acolhimento, o conforto, o suporte, e até mesmo a própria preparação para comunicar aos familiares a morte de seu ente querido, torna-se um processo difícil, com o qual alguns acadêmicos referem não saber como lidar. A gente não tem nenhuma preparasãa para lidar com a morte [...], nem como explicar aos familiares (Acadêmico $A$ ).

Durante a análise das entrevistas consideramos importante a percepção de um acadêmico sobre o que deve ser feito pelo profissional que está assistindo o paciente no momento em que ocorre a morte deste. Para ele [...] no momento da morte o sujeito deve ser o mais amparado possivel [...]. Deveria estar no instante da morte conjuntamente com seus familiares... o profissional tem que dar o suporte necessário naquele instante de morte [...], seja através do silêncio, seja através de estendendo a mão, seja através do olhar [...], o silêncio, o carinho, a atenção é o melhor resultado naquele instante (Acadêmico B).

Outro aspecto importante, evidenciado nas entrevistas, diz respeito à comparação que os entrevistados fizeram entre os seus familiares e o paciente que estava morrendo ou morreu, ou seja, a relação entre a vivência pessoal deles com a morte e a percepção acadêmica. O Acadêmico $\mathrm{E}$ entende que [...] porque en não tive isso na minha família ainda, como é que eu vou reagir? Pode ser que eu venha a ficar muito mal, pode ser que eu encare com uma certa tranqüilidade, mas não saberia como eu agiria neste processo (Acadêmico E).

A percepção dos acadêmicos frente à morte está diretamente relacionada com as vivências pessoais de cada um, sendo que devemos levar em consideração também a idade daquele que morreu, o sexo, a afinidade com os cuidadores e, principalmente, o vínculo que existe entre o paciente e os profissionais. [...] por exemplo, tu está numa UTI e o aluno vê naquele paciente a mãe dele que morreu [...], ou tu vê uma criança, tu é pai, tu vê a forma de ver aquele óbito. Vai ser diferente. Ainda mais se a criança for parecida com o filho que ele tem em casa [...] (Acadêmico B).

Existem fatores individuais que podem vir a prejudicar o diálogo sobre a morte, podendo estes rela- 
cionarem-se com experiências que o indivíduo teve com a morte de pessoas ligadas a ele ou com a proximidade que ele teve com a morte, como fatores religiosos e até mesmo com a maneira que esta religiosidade é vivida por ele, com os sentimentos que ele experimenta ante a expectativa da sua própria morte, entre outros. ${ }^{3}$

As entrevistas evidenciam que os acadêmicos de enfermagem não sabem como agir frente às famílias, tanto de doentes terminais, quanto de pacientes que morreram. Eles demonstraram dificuldade em lidar com o processo morte-morrer dos pacientes assistidos em estágio. Isto denota que as pessoas têm muita dificuldade de lidar com os sentimentos suscitados diante da morte e preferem não se envolver com os familiares, dedicando-se exclusivamente aos cuidados técnicos e burocráticos, fugindo assim de um contato mais próximo.

\section{A morte vista como estigma, tabu e misticismo}

Esta área temática evidencia que os acadêmicos de enfermagem entrevistados percebem a morte como tabu; um assunto que não é falado, discutido, tanto na sociedade como na graduação. Esta realidade, ao ser percebida como algo misterioso, gerador de medo, angústia e ansiedade, nos passa a idéia de que a morte virou realmente um tabu. Para o Acadêmico B [...] $a$ morte é carregada por um estigma muito grande, de um misticismo muito grande, que vem se repetindo em gerações, geraçöes, isso então cria uma concepşão da morte como algo negativo, como algo dolorido, como algo sem solução (Acadêmico B).

O tempo em que vivemos é caracterizado por uma cultura que não problematiza a morte, atitude que faz com que tenhamos dificuldade em lidar com ela, tanto no que diz respeito aos profissionais que trabalham ligados à morte, como também às pessoas em geral. ${ }^{9}$ Cabe a nós mudar esta realidade, vivendo a vida da melhor maneira possível, dialogando sobre a morte com as pessoas e buscando tratá-la como algo inevitável e destinado a todos. [...] a morte é um tabu na graduação, ninguém fala; quando falam é superficialmente, e já fugindo do assunto [...] (Acadêmico H).

Os sentimentos que a morte faz aflorar são tão intensos, que seu nome não deve nem ser pronunciado. Por si só ela causa medo, fuga e espanto. A morte só deixará de ser vista como um tabu, quando as pessoas aceitarem a idéia de que são finitas e de que ela faz parte do ciclo vital, não se podendo dela fugir. ${ }^{3}$ Esta afirmação é corroborada pelo Acadêmico $\mathrm{O}$, quando refere [...] a gente, tanto os professores, como os alunos, tentam fugir um pouco da morte. Essa que é a realidade (Acadêmico O).
A fala anterior confirma a tese de que a sociedade ocidental nega a morte, e a educação que é infundida aos profissionais de enfermagem não se diferencia da que é passada ao restante da sociedade, ou seja, não é trabalhada a questão positiva da morte. Este fator vem fazer com que as pessoas neguem a morte, recusandose a ouvir e falar sobre ela. ${ }^{10}$ Questões como a morte envolvem um reposicionamento não só de uma classe de profissionais, mas sim, da sociedade como um todo, devendo ser discutida e debatida. ${ }^{7}$

Concluímos que a morte é percebida por alguns dos acadêmicos entrevistados como um tabu, um estigma, geradora de sofrimento, não sendo ainda discutida por alunos e professores, o que denota realmente a dificuldade existente em falar sobre este tema. Em plena era da moderna biotecnologia, as pessoas passaram a viver seus últimos momentos em um ambiente completamente desconhecido, sendo assistidos por profissionais que muitas vezes estão despreparados psicologicamente para prestar uma assistência integral. Em decorrência, as escolas formadoras de profissionais da saúde deveriam ampliar o conteúdo didático acerca da morte, pois quando evitamos falar sobre tal acontecimento, estamos apenas "fugindo" do famoso medo do confrontamento com o destino final, a única certeza daqueles que vivem.

\section{O preparo para vivenciar o processo morte- morrer}

Esta área temática busca mostrar como os acadêmicos de enfermagem estão sendo preparados para vivenciar situações que envolvem o processo morte-morrer de seus futuros pacientes. Em vários momentos, os entrevistados questionaram a maneira como estão sendo oferecidos conhecimentos acerca desta temática na graduação.

O Acadêmico B entende que este é um tema pouco discutido, é um tema difícil de falar, então a graduação não prepara, quem se prepara propriamente é o sujeito vivendo a situação, e mesmo que tu enfrenta a teoria de morrer, é diferente que tu enfrentar a prática de morrer. Então é algo assim que deveria ser mais explorado (Acadêmico B).

Estudos sobre morte-morrer demonstram que a justificativa do despreparo em lidar com tal fenômeno é atribuída muitas vezes à formação acadêmica, e salientam ainda que a graduação continua a não preparar os profissionais para vivenciarem o processo. ${ }^{3} \mathrm{Na}$ minha opinião infelizmente a graduação tem pouco suporte para sabermos lidar com a morte, o que nos torna às vezes um pouco frustrados em lidar com estas situações (Acadêmico $G$ ). 
O Acadêmico J relata: na minha jornada acadêmica presenciei duas mortes, então ainda não sei lidar com isso. $O$ professor não deu muita atenção a isto, não sei se porque é normal para ele, só disse para esquecer que a vida é assim (Acadêmico J). O depoimento anterior mostra como o acadêmico se sente despreparado para vivenciar a morte dos pacientes, e como o supervisor de estágio não abordou o assunto. Certamente o professor considera a morte uma conseqüência da vida, porém isto não o isenta $\mathrm{da}$ responsabilidade de proporcionar momentos de reflexão aos alunos. A preocupação com a formação é abordada pelo Acadêmico N: eu acho que a graduação não prepara, ela está se preocupando demais em técnicas, em aprender, em saber o que é, medicação, vamos diluir, vamos fazer, mas psicologicamente para o aluno eu acho que não tendo apoio nenbum, eu até gostaria que tivesse (Acadêmico N).

Defende-se que as escolas de enfermagem e medicina devem "mudar da preparação de praticantes apenas tecnicamente competentes, para profissionais que sejam capazes de lidar com seus próprios sentimentos e usá-los de modo deliberado e humanamente sofisticados". 2:42 Alguns depoimentos indicam que os acadêmicos recordam que o tema foi abordado em algumas disciplinas, porém consideram insuficiente tal abordagem. Para o Acadêmico O: infeližnente a graduação não nos proporciona o esclarecimento deste processo, é lógico que estudamos sentimentos de perda e separaşão em aulas de psicologia e saúde mental, mas o que fazer, on qual a atitude do enfermeiro diante desta situação não (Acadêmico O).

Ao finalizar esta área temática, concluímos que os acadêmicos de enfermagem entrevistados percebem uma carência no que diz respeito ao preparo deles para vivenciar o processo morte-morrer, sendo esta carência relacionada principalmente à questão emocional. As entrevistas evidenciam que a graduação oferece um satisfatório preparo quanto aos procedimentos técnicos, deixando uma lacuna no tocante aos aspectos psicológicos. Outro dado observado nas entrevistas foi que não é oferecido suporte emocional aos acadêmicos que vivenciaram a morte em campo de estágio, o que é explorado na próxima área temática.

\section{Apoio oferecido pelo professor supervisor em campo}

Esta área temática traz uma abordagem à questão do suporte oferecido pelos professores supervisores aos acadêmicos que vivenciaram a morte em campo de estágio. $\mathrm{O}$ Acadêmico $\mathrm{O}$ relata: [...] eu não recebi apoio nenbum, simplesmente o cara morreu e pronto, o professor não falou nada, acho que também por que não precisou, para mim, foi norma (Acadêmico O). Para o Acadêmico E, quando aconteceu isso, simplesmente o cara morreu, não foi comentado..., não tive nenhum suporte. Eu acho que nenhum professor dá esse suporte (Acadêmico E).

Ao proporcionar ao acadêmico um esclarecimento sobre o que realmente é a morte, o professor enriquece o conhecimento do acadêmico acerca de tal processo. Se cada um dos docentes realizasse momentos de reflexão e supervisão após as primeiras experiências dos alunos com a morte, estes sentir-se-iam mais seguros e preparados para conviver futuramente com tal ocorrência. O Acadêmico F diz: [...] em todos os meus estágios, eu vi duas pessoas morrerem... eu não tive apoio nenhum, de nenbum tipo e em momento nenbum (Acadêmico F).

Ao trabalharmos com colegas que sentem dificuldades em relação ao processo morte-morrer, o ato de conversarmos, ouvirmos as preocupações deles é uma forma de lhes prestarmos apoio e ajuda. ${ }^{11}$ Porém, infelizmente, percebemos através dos relatos que muitos professores não oferecem esta abertura aos acadêmicos, e que mesmo entre eles não existe um diálogo para troca de experiências e esclarecimento de dúvidas. O Acadêmico A refere que [...] o professor não oferecen apoio nenbum, como se nada estivesse acontecendo... simplesmente morreu, morreu, não deram suporte nenhum pra gente (Acadêmico A).

Os alunos necessitam do apoio de alguém nas suas primeiras experiências profissionais (graduação), para que, através deste suporte, eles consigam organizar seus sentimentos e também agir como profissionais, sem se sentirem defasados no tocante às sensações. Alguns relatos evidenciam que alguns professores supervisores não vêm oferecendo apoio aos acadêmicos que experienciam a morte. Tal fato pode ser atribuído à própria negação dos sentimentos pelo professor, à prevalência de ações técnicas em detrimento de um cuidado humanizado, não só em relação ao paciente e familiares, mas também aos acadêmicos envolvidos. ${ }^{12}$ Segundo o Acadêmico L: ela não me deu suporte nenbum, o que eu vivenciei foi em clínica, então eu acho que ela não me deu suporte porque ela não conversou conosco, ela só pediu o que tinha acontecido, e não falou mais nada, tipo morreu, morreu, não tem mais importância entendeu... o que dificulta não só ao ver um paciente morrer, como em ter que dar a notícia para o familiar (Acadêmico L).

"Cabe ao educador a preocupação sobre a personalidade saudável dos educandos, essa qualidade é imprescindível ao profissional da área da saúde, porque o ser humano tem o poder de afetar o destino da sua personalidade apesar dos fatores genéticos, ambientais e sociais, quando pessoas devem ser facilitadoras do seu desenvolvimento". ${ }^{12: 102} \mathrm{O}$ Acadêmico Mexpõe: vivenciei 
duas mortes e nunca tive suporte durante o momento. Tive que refletir e entender sozinha (Acadêmico $M$ ).

Evidenciou-se que alguns professores proporcionaram aos acadêmicos que vivenciaram a morte em campo de estágio, uma abertura para falar e ouvir sobre o processo morte-morrer. Porém, a grande maioria dos entrevistados referiu não receber apoio nenhum, tendo que refletir sozinhos ou com colegas. Ficou evidente, também, que a maneira como cada um percebe tal fenômeno é diferente, para alguns a morte é vista como processo normal, enquanto para outros foi uma experiência difícil de ser superada.

\section{Os sentimentos experimentados pelos acadêmicos que vivenciaram a morte em campo de estágio}

Esta área temática aborda os sentimentos suscitados com a morte. Percebemos que a morte é capaz de gerar muitos pensamentos dirigidos à emoção, até mesmo quando os indivíduos são levados apenas a refletir sobre a mesma. Entre os sentimentos comumente expressos foram encontrados o abalo, o medo, a frustração, a culpa, o choque e a angústia. Para o Acadêmico B, acima de tudo a maioria aceita a morte, on pelo menos tenta aceitar, porque se tu não aceitar, tu cria uma grande frustração naquele instante, até pode ser uma frustração, dependendo de como você encara a situação (Acadêmico B).

Os sentimentos mais comuns frente à morte são $a$ impotência, aculpaea raiva, vivenciadoscom muitador, o que determina que alguns profissionais ou até mesmo acadêmicos da área da saúde mantenham-se distantes dos doentes terminais, ou até mesmo do momento da morte de algum paciente devido aos sentimentos de culpa ou até de impotência. ${ }^{13-14}$ Estes sentimentos são relatados pelo Acadêmico D: [...] eu vivi com distanciamento, eu não quis chegar perto, fiquei com medo de ficar impressionada com aquilo, não me aproximei (Acadêmico D).

A tendência, quando não sabemos enfrentar determinada situação, é a de nos afastarmos dela, a fim de nos precavermos de sentimentos como o medo, a culpa e até mesmo a sensação de fracasso por não termos conseguido fazer nada mais para evitar tal desfecho. A experiência da perda é dolorosa, ameaçadora e solitária, podendo gerar nos indivíduos diversas reações emocionais, como negação, raiva, choque, inércia, ansiedade, depressão e angústia espiritual. ${ }^{11} \mathrm{~A}$ fala do Acadêmico E identifica esta situação, ao relatar: [...] já escutei colegas minhas dizerem que tem pesadelos, que não conseguem dormir direito, que sentem a pessoa lá quando ela está morrendo, então é bem complicado... até muitas vezes aquele sentimento que o cara não sabe explicar o que, é que tu fica com aquele aperto no coração que tu não sabe explicar o que é (Acadêmico E).

"Ao estar presente no momento da morte de um paciente, o aluno se envolve emocionalmente, não interessando o grau deste envolvimento e a intensidade da emoção gerada, respondendo de maneira particularà estrutura decada um". 12:102 O Acadêmico A reconhece: [...] muitos dos meus colegas ficaram abalados, principalmente os que nunca tinham vivenciado a morte de uma pessoa... que dá para notar bem quem trabalha no bospital já tem uma noção, já viu um paciente morrer, agora aqueles que nunca tiveram, nunca viram, ficam completamente perdidos (Acadêmico A). O Acadêmico O constata: [...] percebi que pelo fato de nossos supervisores já terem vivenciado várias mortes e já estarem preparados para este processo não se preocuparam conosco, acadêmicos, com o choque que tal fato pode ocasionar na morte, os sentimentos do aluno, penso que isto pode ser um motivo para um aluno que está ainda em dúvida sobre o curso que escolheu para sua vida profissional implicar em desistência do mesmo (Acadêmico O).

Conclui-se, portanto, que os acadêmicos entrevistados têm grande dificuldade em reconhecer seus próprios limites. Para alguns a morte é um processo natural, que atinge a todos, sendo que tais entrevistados dizem ter vivenciado tal fenômeno com normalidade, enquanto outros relataram a dificuldade em superar tal acontecimento, mostrando em suas falas os sentimentos de ansiedade, culpa, impotência e angústia gerados pela experiência.

\section{Conhecimento/desconhecimento das fases psicológicas}

Esta área temática demonstra o conhecimento dos acadêmicos de enfermagem entrevistados acerca das fases psicológicas pelas quais passa o doente terminal. O conhecimento destas fases é muito importante para que possam auxiliar tanto os pacientes quanto as suas famílias.

O Acadêmico A utilizou um exemplo para explicar o seu conhecimento sobre as fases psicológicas: [...] bom, eu vou citar o exemplo de uma amiga minha... primeiro ela teve a doença e não aceitou... depois ela achou que estava curada... começou piorar e ainda não aceitava que tinha a doença, diæia que não era nada, dai ela quase morreu, procurou tratamento... agora ela está aceitando bem, lutando para viver (Acadêmico A). O acadêmico soube identificar algumas etapas pelas quais o doente terminal passa, porém não tem conhecimento científico das mesmas, reportando-se a uma vivência empírica para responder à questão.

Para o Acadêmico B: deve ter em livros, mas nunca me aprofundei nisso, já ouvi falar.. é que se tu vai ver depende que caso 
que ele é, que patologia está... depende da construção de cada um, cada um vivencia a morte de forma diferente (Acadêmico B).

A respeito disso questionamo-nos sobre a maneira como um enfermeiro poderá atuar frente a este processo, se não tem conhecimento da real situação psicológica em que se encontra o paciente e a família. As entrevistas de dois Acadêmicos, evidenciam esta dificuldade: [...] eu não entendendo muito bem, não tenho nenhum conhecimento, sei que tem fases de negação, de tristera, tem fases que a pessoa fica mais esperançosa, mas assim exatamente não tenho conhecimento (Acadêmico C).

[...] negação, um pouco de raiva, en acho que se en tivesse numa fase terminal, eu acho que seria mais de revolta ou negação dessa doença e eu acho que a pessoa depois de preparada tenta conseguir alguém que the dê atenção, acho que a pessoa acaba quase no final ali, aceitando essa doença (Acadêmico F).

Os depoimentos mostram que os acadêmicos entrevistados não sabem como auxiliar os doentes terminais. Ao identificarmos a fase na qual o paciente se encontra, poderemos oferecer a ele não só apoio, mas também a compreensão das suas atitudes e comportamentos, muitas vezes direcionados à equipe através da agressividade.

A falado Acadêmico Hapresenta a realidade que comumente encontramos, pois muitas vezes a equipe multiprofissional trata o paciente pelo seu diagnóstico, ou seja, a pessoa deixa de ser chamada pelo seu nome para ser taxada pela doença que possui. Sei que existem as fases, como também sei que podem não ocorrer em uma única ordem para todos, agora com toda certeza falar sobre elas en não sei. Existe a fase de negação... a outra é a barganha, outra ele se vê e é visto como a doença e não mais como alguém, por exemplo o João deixa de ser João e passa a ser o canceroso, a ultima é a aceitação (Acadêmico H).

Conclui-se que os acadêmicos não têm nenhum conhecimento científico a respeito do assunto abordado. Muitos até sabem reconhecer empiricamente as alterações psicológicas que os pacientes terminais apresentam, porém não sabem com exatidão o que cada uma representa e de que maneira podem ser trabalhadas. Tais dados mostram que os acadêmicos não têm incluída tal abordagem em seu conteúdo, ou, se têm, não é feita uma aproximação com a prática clínica, deixando uma lacuna acerca das reações daqueles que vivem a sua terminalidade.

\section{CONSIDERAÇÕES FINAIS}

A realização deste estudo evidenciou que os acadêmicos de enfermagem entrevistados possuem opiniões variadas acerca do tema morte-morrer. Os achados deste trabalho corroboraram o pressuposto de que os acadêmicos de enfermagem não estão preparados para vivenciar o processo morte-morrer de seus futuros clientes, devido às poucas oportunidades de discutir tal tema na graduação. As entrevistas evidenciam que os graduandos desejam prestar um cuidado humanizado aos pacientes terminais, bem como às famílias que acompanham este processo, porém, a maioria dos entrevistados sente dificuldades em lidar com tal situação, não sabendo como abordar os familiares e menos ainda como lidar com os próprios sentimentos.

Constatamos também que a graduação não vem oferecendo um bom preparo para que os acadêmicos realizem tais cuidados; vários deles salientaram a importância de ser discutido, tanto em sala de aula como em campo de estágio, o assunto morte-morrer. Alguns relataram que a graduação dá mais ênfase às técnicas de enfermagem e ao cuidado com o corpo físico do paciente, deixando uma lacuna no que diz respeito ao cuidado psicológico que deveria ser oferecido aos pacientes e familiares. Entendemos que ser enfermeira prestadora de assistência aos doentes terminais, bem como a seus familiares, é vivenciar diariamente tal desafio, é fazer-se presente no espaço subjetivo externo e no espaço subjetivo interno, isto é, compor-se na paisagem daquele paciente e na da sua família.

Concluindo, trazemos as sugestões apontadas pelos acadêmicos entrevistados a fim de melhorar seu preparo para vivenciar situações que envolvam o processo morte-morrer: a inclusão da temática na grade curricular, a troca de experiência entre professores e alunos; a realização de grupos para debater o assunto; um aprofundamento sobre o tema nas disciplinas de Psicologia; a presença da temática em seminários ou cursos de extensão; a enfatização na questão sobre como agir e atuar frente à morte e na comunicação desta aos familiares; um olhar mais atento do professor supervisor aos acadêmicos que experienciam a morte em campo de estágio; e um horário de supervisão no final de cada dia de estágio para que os acadêmicos possam dialogar com o professor supervisor sobre as diversas experiências vivenciadas.

\section{REFERÊNCIAS}

1 Pessini L. Problemas atuais de bioética. São Paulo (SP): Loyola; 2000.

2 Kübler-Ross E. Morte: o estágio final da evolução. Rio de Janeiro (RJ): Record; 1975.

3 LunardiFilhoWD, SulzbachRC;NunesAC,LunardiVL. Percepções e condutas dos profissionais de enfermagem 
frente ao processo de morrer e morte. Texto Contexto Enferm. 2001 Set-Dez; 10 (3): 60-79.

4 BrazE, Fernandes LM. Buscando maneiras para o ensino sobre finitude para graduandos de enfermagem. Texto Contexto Enferm. 2001 Set-Dez; 10 (3): 138-41.

5 Minayo MCS. O desafio do conhecimento-pesquisa qualitativa em saúde. São Paulo (SP): Hucitec; 2000.

6 Ministério da Saúde (BR), Conselho Nacional de Saúde, Comitê Nacional de Ética em Pesquisa com Seres Humanos. Resolução No 196 de 10 de outubro de 1996: diretrizes e normas regulamentadoras de pesquisa envolvendo seres humanos. Brasília (DF): O Conselho;1996.

7 Beck CLC. O processo de viver, adoecer e morre. São Paul (SP): Martins Fontes; 2002.

8 Kübler-Ross E. Sobre a morte e o morrer. São Paulo(SP): Martins Fontes; 2002.
9 Klafke ET. O médico lidando com a morte: aspectos da relação médico-paciente terminal em cancerologia. In: Cassorla SR, organizador. Da morte: estudos brasileiros. Campinas (SP): Papirus; 1991. p.38-52.

10 Pinheiro LMG; Dias JAA; Araújo RT; Oliveira Z. Percepções de enfermeiras(os) docentes acerca da morte. Rev. Enferm. Atual 2004 Mar-Abr; (20): 27-32.

11 BrunnerLS, SuddarthDS. Tratadodeenfermagemmédicocirúrgica. Rio de Janeiro (RJ): Guanabara Koogan; 2001.

12 Carpena BAL. Morte versus sentimentos: uma realidade no mundo dos acadêmicos de medicina. Rev. Gaúcha Enferm. 2000 Jan; 21 (1): 100-22.

13 Santos CAF. Os profissionais de saúde enfrentam-negam a morte. In: Martins JS. A morte e os mortos na sociedade brasileira. São Paulo (SP): Hucitec; 1983. p.15-24.

14 Consorte J. A morte na prática médica. In: Martins JS. A morte e os mortos na sociedade brasileira. São Paulo (SP): Hucitec; 1983. p.38-57. 